\title{
Algumas teorias para discutir o desenvolvimento
}

\author{
Some theories to discuss development
}

\author{
Marines Rute Oliveira ${ }^{\mathrm{I}}$
}

\begin{abstract}
Resumo
Este artigo busca contribuir com conceitos e definições de desenvolvimento abordados em variadas obras de conceituados autores que trabalham essa temática, dando um destaque aos conceitos de desenvolvimento como liberdade - definido por Amartya Sen e, também, o conceito de desenvolvimento sustentável, assim como são expostos os aspectos históricos descritivos de desenvolvimento rural e regional. objetivo é trazer conceitos que auxiliam no entendimento do assunto aqui abordado, para que haja uma melhor compreensão do tema. Salientando que esse artigo faz parte de uma revisão bibliográfica que é uma parte de estudos para fins de elaboração de tese de doutoramento, que tem como eixo de reflexão o desenvolvimento como liberdade, no sentido de analisar o desenvolvimento rural do oeste do Paraná a partir da agricultura familiar. Argumenta-se que as considerações finais ainda estão em construção e foram apresentadas, aqui, somente um breve resumo das mesmas.
\end{abstract}

Palavras- Chave: Desenvolvimento; Desenvolvimento Regional; Desenvolvimento Rural

\begin{abstract}
This article seeks to contribute to concepts and definitions of development addressed in various works by renowned authors who work on this theme, highlighting the concepts of development as freedom - defined by Amartya Sen and also the concept of sustainable development, as well as the descriptive historical aspects of rural and regional development are exposed. objective is to bring concepts that help in the understanding of the subject addressed here, so that there is a better understanding of the subject. Emphasizing that this article is part of a bibliographic review that is a part of studies for the purpose of elaborating a doctoral thesis, whose axis of reflection is the development as freedom, in the sense of analyzing the rural development of western Paraná from the family farming. It is argued that the final considerations are still under construction and were presented here only a brief summary of them.
\end{abstract}

Keywords: Development; Regional development; Rural Development 


\section{Introdução}

Inicialmente, serão apresentadas algumas definições e conceitualizações de desenvolvimento, exposto um breve panorama sobre as constribuições de Amartya Sen para a discussão de questões econômicas e sociais, sobretudo as relacionadas ao desenvolvimento. Posteriormente, apresenta-se, de forma sintetizada, as teorias de desenvolvimento regional e algumas definições e discussões sobre o desenvolvimento rural. Por fim, serão dispostas as considerações finais desse trabalho.

De acordo com Gustavo Esteva (2000, p. 61): "Não há nenhum outro conceito no pensamento moderno que tenha influência comparável sobre a maneira de pensar no comportamento humano. Ao mesmo tempo, poucas palavras são tão ineficazes, tão frágeis e tão incapazes de dar substância e significado ao pensamento e ao comportamento."

Enquanto que para Amartya Sen (2000 p.11) o desenvolvimento pode ser definido como sendo "um processo de expansão das liberdades reais que as pessoas desfrutam". Desta forma, a sua concepção de desenvolvimento é visto como um meio das pessoas desempenharem sua condição de agente obtendo autonomia sobre suas vidas (SEN, 2002).

Para Neuro Jose Zambam (2016), o desenvolvimento sustentável pode ser entendido com as aplicações do conceito de sustentabilidade no âmbito político-econômico-social. Uma definição estipulada por Ademir Clemente e Hermes Higachi (2000) é a de que o mesmo é visto como sendo a elevação do nível de vida da população, tendo por base o desenvolvimento autossustentado, em que as riquezas naturais da região, juntamente com o fator humano, ou seja, seus costumes, culturas e práticas, adaptam a economia aos moldes de suas particularidades.

Conforme Kageyama (2004), o desenvolvimento rural pode ser considerado como um procedimento que engloba os aspectos econômico, social, cultural, político, institucional e ambiental e não somente relacionado ao crescimento econômico visto por meio do aumento do PIB ou da renda.

\section{Conceitos e definições de desenvolvimento}

Inicia-se postulando que o desenvolvimento contemporâneo teve sua origem no campo teórico na fase do mercantilismo. Embora, conforme Robert Nisbet (1985), a idéia de progresso possa ser identificada já no pensamento clássico grego e romano tanto nas artes quanto nas ciências, em que há deferência e aceitação pelo conhecimento prático relacionado à proteção e ao bem-estar para todos, adquirido a partir de suas aptidões próprias ocorridas por meio do tempo, de forma acumulativa e gradualmente.

Desde os pensadores clássicos, como Adam Smith, por exemplo, discutia-se o entendimento de que a principal causa geradora das riquezas das nações encontrava-se no trabalho produtivo. Porém, para os pensadores clássicos, o crescimento e o desenvolvimento eram entendidos como sinônimos. Contrário a isso, Karl Marx foi o primeiro a dar a sua contribuição ao diferenciar crescimento de desenvolvimento. Para ele, o sistema econômico era dividido em duas classes sociais: a classe capitalista - proprietária dos meios de produção; e a classe trabalhadora - detentora da força de trabalho. E, ainda, afirmava que a primeira classe explorava a segunda por meio da mais-valia. John Maynard Keynes também procurou diferenciar o conceito de crescimento econômico e de desenvolvimento econômico, centrando sua análise na abordagem macroeconômica do emprego e nos fatores de crescimento econômico, de acordo com Argemiro Brum (2002).

A partir de outra perspectiva de análise, Joseph Schumpeter (1982) afirmava que o crescimento econômico ocorreria quando as atividades econômicas acontecessem de forma normal por meio de um fluxo de equilíbrio em que se produziria para obter lucros. No entanto, foi só após a crise econômica de 1930 e a Segunda Guerra Mundial que houve alterações na realidade dos países, ocorrendo uma nova forma de gestão tanto na ordem econômica quanto na ordem política. Com a utilização da contabilidade nacional e com base nos indicadores econômicos e sociais, foi possível fazer a divisão entre os países desenvolvidos e os subdesenvolvidos, em que os problemas relacionados à inflação e ao desemprego deram margem ao surgimento de novas interpretações às dinâmicas das economias mundiais. A partir de então, passou-se a tratar o crescimento econômico como elemento importante, todavia, não único no processo, uma vez que a qualidade de vida dos indivíduos passou a assumir nuances diversas daquelas previamente observadas.

Trazendo algumas definições acerca do pensamento em relação ao desenvolvimento, nota-se que há uma variada gama de referências destes movimentos. Não se pretende esgotar essa temática, mas simplesmente destacar que a visão sobre este assunto vem se alterando com o decorrer da história e esse vem tentando se adaptar de acordo com as alterações ocorridas nos âmbitos políticos, sociais, tecnológicos e ambientais nas quais a sociedade vem passando.

Sabe-se que a fisiocracia foi uma das primeiras escolas de pensadores do desenvolvimento, cujo objeto de pesquisa era a geração da riqueza das nações que ocorria por meio da produção, sobretudo a agrícola. Em seu livro Tableau economique des phiysiocrates, François Quesnay (1996) destacou que a classe produtiva rural, por meio do seu cultivo, gerava as riquezas da nação. Enquanto que a escola clássica do século XVIII representada por Adam Smith (1996) também tinha por objeto de estudo as causas que levavam ao desenvolvimento. No entanto, os autores contestavam os princípios da fisiocracia e defendiam a questão do valor-trabalho como sendo a causa essencial para o desenvolvimento da nação, em que os ganhos de produtividade que vinham da divisão e da especialização do trabalho geraria a acumulação de riquezas. 
Com o decorrer do tempo, outros teóricos como Thomas Malthus (1996), David Ricardo (1996), Alfred Marshall (1996) e Joseph Schumpeter (1982), entre outros, trouxeram para a discussão do desenvolvimento outros aspectos econômicos fundamentais. Abordaram questões como a relação entre crescimento populacional e produtivo; idéias referentes ao valor do trabalho; questões industriais como forma de expandir a capacidade e eficiência da produção; a relevância tecnológica e a função do empreendedor. Todas essas questões acabaram por influenciar estudos acerca do desenvolvimento.

Já para os autores Arbix et all (2001), as políticas desenvolvimentistas do século XX não seriam capazes de promover o desenvolvimento do século XXI, pois havia uma necessidade de novas estratégias, uma vez que o sistema econômico já era dinâmico. No entanto, o que eles salientam como importante é que esses novos modelos de desenvolvimento traziam em seu bojo a noção de eliminação da pobreza e da desigualdade.

Nota-se que, conforme a corrente de pensamento em que se enquadram, as definições de desenvolvimento sofrem variações.

Assim, na teoria de desenvolvimento como liberdade é argumentado que quando se utiliza apenas a noção de utilitarismo não é levado em consideração a relevância primordial das ações e motivações das pessoas e o seu papel enquanto agentes. Assim, Sen (2000), considera que o bem-estar é definido, nesta concepção utilitarista, a partir da felicidade, do desejo e da escolha. Onde a utilidade é vista como uma interpretação matemática da forma de escolha das pessoas e não se considera as motivações para a busca do bem-estar, uma vez que as pessoas não são levadas apenas pela procura do bem-estar individual.

O autor considera ainda, que analisar o bem-estar por meio do desejo e satisfação aumenta o risco de erros na interpretação, uma vez que as pessoas, em determinadas circunstâncias, podem controlar seus desejos para obter um nível de satisfação "As pessoas aprendem a ajustar-se aos horrores existentes; pela pura necessidade de sobrevivência sem intercorrências" (Sen,1998, p. 309).

Sen (1997) descreve sobre o erro que recai ao compreender o desenvolvimento apenas como um meio de fazer com que as pessoas sejam mais produtivas, ou seja, visar a melhoria do capital humano, considerando as pessoas somente como meios de produção ao invés de serem vistos também como o objetivo fim de todo o processo.

A concepção de Sen (2000 p.11) sobre o que vem a ser o desenvolvimento está relacionada ao fato dele definir como sendo "um processo de expansão das liberdades reais que as pessoas desfrutam".

Observa-se que o enfoque nas liberdades humanas se contrapõe com a usual interpretação limitada de desenvolvimento que faz relação direta com o crescimento econômico por meio de variáveis como o PIB, PNB, elevação da renda per capita, melhora na industrialização e no progresso técnico. Desta forma, ao pressupor o desenvolvimento como expansão das liberdades substantivas, ocorre uma direção da ação voltada para os fins e também para os meios de se obter esse desenvolvimento.

Sen argumenta ainda, que a utilidade da riqueza está nas liberdades que ela ajuda a obter. Assim, não dá para desconsiderar a acumulação e o crescimento, mas se torna necessário ir além: "se temos razões para querer mais riqueza, precisamos indagar: quais são exatamente essas razões, como elas funcionam ou de que elas dependem e que coisa podemos "fazer" com mais riqueza?" (Sen, 2000 p. 12). Para o autor, se o desenvolvimento promove a liberdade, isso justifica o foco neste objetivo e não somente nas variáveis que podem ser consideradas os meios para que o desenvolvimento ocorra. Temos, com isso, que o poder efetivo de realização das pessoas tem influência direta das suas oportunidades que se traduzem pelos meios econômicos, de suas relações sociais, suas liberdades políticas, do seu acesso à saúde e alimentação e também demais incentivos para suas iniciativas.

Assim, Sen (2000) argumenta que a liberdade é fundamental para o processo de desenvolvimento quer seja por sua razão avaliatória, ou seja, observar se há uma relação entre o progresso e o aumento de liberdades das pessoas, ou por sua razão de eficácia, em que o desenvolvimento é dependente da condição de agente das pessoas. O autor cita alguns exemplos de liberdade para demonstrar a importância de ter a liberdade como objetivo fim e meio do desenvolvimento, entre eles, a liberdade de participação política e de receber educação e assistência médica, e esclarece que esses itens são importantes não só como resultado do desenvolvimento, ou seja, esperar que o crescimento ocorra para, então, as pessoas terem acesso, mas como meio, quer dizer: o desenvolvimento ocorrerá porque as pessoas estão tendo essas expansões de liberdade.

Ter o desenvolvimento como um meio integrado de expansão de liberdades relacionadas umas às outras faz com que seja possível verificar o papel de diversas organizações como o Governo, o Mercado, os Partidos Políticos, as Instituições Civis, os Meios de Comunicação, o Sistema Educacional entre outros. Reconhecer a função desses fatores torna-se primordial para a verificação das liberdades que as pessoas usufruem e buscam manter. Assim, os valores dominantes e os costumes sociais influenciam no exercício da liberdade que podem ser classificados como: políticos, econômicos, sociais, segurança e transparência. A junção dessas liberdades leva ao desenvolvimento como liberdade.

Sen (2000) expõe que a utilidade da riqueza está nas coisas que elas nos permite fazer, ou seja, nas liberdades substantivas que obtêm-se com elas, salientando que há outras formas de influências à vida e não apenas a riqueza, e o impacto causado por ela pode variar de acordo com outros influenciadores:

“É tão importante reconhecer o papel crucial da riqueza na determinação de nossas condições e qualidade de vida quanto entender a natureza restrita e dependente dessa relação. Uma concepção adequada de desenvolvimento deve ir muito além da acumulação de riqueza e do crescimento do Produto Nacional Bruto e de outras variáveis relacionadas à renda. Sem desconsiderar a importância do crescimento econômico, precisamos enxergar muito além dele". (Sen, 2000p. 28). 
Nota-se que o autor critica as análises tradicionais de desenvolvimento que focam na eficiência e negligenciam a equidade, atribuindo maior importância na desigualdade de rendimento e desconsiderando outros aspectos importantes relacionados às capacitações e liberdades individuais, que são influenciados por variáveis como a heterogeneidade pessoal, as variedades ambiental, cultural e social.

O autor destaca, ainda, a importância da participação ativa, em que os indivíduos são levados à condição de agentes e destaca também a necessidade das análises da pobreza serem direcionadas para as potencialidades. Assim, a abordagem correta para a verificação de recursos e consequente desenvolvimento deve direcionar-se para as condições reais tanto dos serviços públicos quanto das particularidades da sociedade que influenciam as escolhas individuais.

O mesmo autor continua expondo que uma consequência do não desenvolvimento é o processo recorrente da carência alimentar, ou seja, a crise da fome. Este problema está relacionado ao funcionamento da economia como um todo e é resultado da concentração de recursos financeiros, produtivos e de propriedade, das possibilidades de produção, da falta de capacidade em utilizar novas tecnologias, da impossibilidade de empregar a força de trabalho, de adquirir e de utilizar o conhecimento.

Diante disto, o desenvolvimento compreende a extinção de carências como a fome, assim como a sua prevenção, considerando que esta questão é de grande relevância no conceito de desenvolvimento como liberdade, uma vez que analisa a segurança e a proteção das pessoas. "o crucial ao analisar a fome é a liberdade substantiva do indivíduo e da família para estabelecer a propriedade de uma quantidade adequada de alimento, o que pode ser feito cultivando-se a própria comida (como fazem os camponeses) ou adquirindo-a no mercado (como fazem quem não cultiva alimentos)" (SEN,2000 p. 189).

Essa ideia de desenvolvimento como liberdade foi utilizada por outros autores anteriormente, como Adam Smith, que retratou as liberdades humanas fundamentais; Karl Marx, que destacou a importância de substituir a dominação das circunstâncias e do acaso sobre os indivíduos pela dominação dos indivíduos sobre as circunstâncias e o acaso; Stuart Mill que protegia e fomentava a liberdade, entre outros autores. Todos davam importância à liberdade de escolha como um critério para o desenvolvimento. "Na verdade, a crença de que o aumento da liberdade é essencialmente um importante fator motivador para avaliar a mudança econômica e social não é nem um pouco nova" (SEN, 2000 p. 309).

Nesta abordagem aqui apresentada, o desenvolvimento é visto como um processo de expansão das liberdades das pessoas, em que busca-se o fortalecimento dessas liberdades e o empenho social em fazer com que elas ocorram. Deste modo, o desenvolvimento, nesta perspectiva, é um comprometimento com a ocorrência da liberdade.

Finalizando, Sen $(2011$, p. 261) reitera que: "ao avaliarmos nossas vidas, temos razões para estarmos interessados não apenas no tipo de vida que conseguimos levar, mas também na liberdade que realmente temos para escolher entre diferentes estilos e modos de vida.".

Com relação ao desenvolvimento sustentável, tem-se que as primeiras referências a desenvolvimento sustentável começaram a surgir em 1972, durante a primeira conferência da ONU- Organização das Nações Unidas sobre meio ambiente e desenvolvimento, em Estocolmo, na Suécia. O termo utilizado, então, foi ecodesenvolvimento e, em 1988, a Comissão Mundial sobre Meio Ambiente e Desenvolvimento, apresentou o documento "Nosso Futuro Comum", mais conhecido como "Relatório Brundtland".

Passou-se, então, a utilizar a expressão desenvolvimento sustentável, com a seguinte definição: "forma como as atuais gerações satisfazem as suas necessidades sem, no entanto, comprometer a capacidade de as gerações futuras satisfazerem suas próprias necessidades". Agora, a partir disso, procura-se o equilíbrio entre desenvolvimento e preservação ambiental, que busca a junção entre desenvolver e ser sustentável, diminuindo as desigualdades sociais e a preservação dos recursos naturais. (COMISSÃO MUNDIAL SOBRE MEIO AMBIENTE E DESENVOLVIMENTO, 1988, p. 46).

De acordo com Patrícia Kranz (1997), o conceito de desenvolvimento sustentável foi construído na década de 1970, com base no discurso de alerta dos movimentos ambientalistas, resultado do progresso sem limite, praticado até aquele momento. A partir de então, começou a se pensar na ideia de um modelo de desenvolvimento que atendesse às necessidades do presente sem comprometer a qualidade das gerações futuras.

Assinala-se que foi a partir da década de 1970 que as modificações ambientais tornaram-se evidentes e essas estão relacionadas ao crescimento populacional, ao uso não planejado dos recursos naturais, à perda da biodiversidade, às migrações populacionais não organizadas, às poluições do ar devido à utilização de combustíveis fosseis e aos processos industriais, aos problemas hídricos e de solo que comprometem a qualidade de vida da sociedade, além do modelo de consumo e consequente produção de resíduos sem um controle adequado.

Porém, “apesar da sustentabilidade ser muitas vezes vista como ideia recente, na verdade, suas origens não se encontram na sociedade industrial, mas nas sociedades indígenas e tradicionais, que sempre basearam suas vidas no conceito de sustentabilidade" (KRANZ, 1997, p. 12).

Deste modo, vale enfatizar que a busca pelo desenvolvimento sustentável não significa negar a importância do crescimento econômico para a prosperidade das nações, mas sim dar um sentido de maior amplitude ao conceito de prosperidade, incluindo a melhoria da qualidade de vida da população e a preservação dos ecossistemas, ou seja, um estudo de desenvolvimento em que o crescimento econômico seja ambientalmente saudável e economicamente justo e equitativo (VARGAS, 2002).

Junto com o avanço dos conceitos, das discussões e dos entendimentos a respeito do desenvolvimento sustentável, foram ocorrendo melhorias nas pesquisas sobre o assunto com novas abordagens teóricas e metodológicas. 
Objetivando a observação, o entendimento, a explicação e a avaliação do desenvolvimento sustentável, assim como as consequências causadas pelas mudanças do meio ambiente em diversas áreas, sobretudo na produtiva.

Neste momento, surgem inquietações relativas à noção de que o desenvolvimento sustentável engloba uma variada gama de aspectos ligados à atividade humana: econômico, produtivo, cultural, ético, político e religioso.

Ignacy Sachs (2001 p. 159) destaca que "o desenvolvimento genuíno requer soluções que atendam a três frentes: que sejam sensíveis ao social, ambientalmente prudentes e economicamente viáveis”. Com tudo isso, há a necessidade de se obter soluções que transitem em variados meios de ações.

\section{Teorias e conceitualizações de desenvolvimento regional e rural}

Para analisar o desenvolvimento de uma região, é necessário levar em conta que as economias regionais não são modelos menores das economias nacionais, pois elas têm especificidades que demandam teorias próprias para esclarecer seu desenvolvimento.

É evidente que as políticas macroeconômicas e setoriais não podem ser consideradas não influentes em termos de impactos espaciais, mas sim que precisam passar por um processo de adaptação em seu planejamento e aplicação. Nota-se que, no Brasil, os conflitos de interesses são algo histórico tanto em termos inter-regional como intraestadual.

As divergências econômicas resultantes das desigualdades regionais de desenvolvimento podem ser vistas como um motivo para esses conflitos de interesses regionais e os diversificados ciclos econômicos justifica esta situação, considerando que os desarranjos regionais já se tornaram um problema estrutural e frequente que nutre essas diferenças (HADDAD,1989).

Ainda de acordo com Paulo Roberto Haddad (1989), a economia regional pode ser definida como o estudo da diferenciação e a inter-relação de áreas em um meio onde os recursos não são igualmente distribuídos e nem perfeitamente móveis, onde a prioridade passa a ser a aplicação em planejamentos de investimentos na área social, com o objetivo de diminuir os problemas sociais já estabelecidos.

Sabe-se que na teoria econômica tradicional, os aspectos espaciais não eram considerados em suas análises, ocorria uma relação não espacial baseada na estagnação da economia com relação aos diversos locais.

Assim, as questões espaciais foram negligenciadas em um longo período. Ao não considerar o espaço, acreditava-se que o tempo deveria ser o enfoque substancial da análise econômica, uma vez que o espaço se dava como secundário em comparação ao fator tempo. Pensava-se, então, que as questões espaciais estariam englobadas na análise tradicional (RICHARDSON, 1981).

Desta forma, o maior interesse pelas consequências advindas da localização e do território em relação à produção econômica veio por meio do experimento na busca por explicar os fatores determinantes no processo de concentração de atividades produtivas em determinados espaços, assim como da maior ação e da habilidade de competição de alguns locais (CAVALCANTE, 2004).

O referido autor propõe uma sistematização das teorias regionais em três grupos: as teorias clássicas de localização; as teorias que enfatizam os fatores de aglomeração; e as que incorporaram temas atuais como a globalização, a desregulamentação econômica e os modos de produção relacionados com a integração e a flexibilidade.

Encaixam-se, no primeiro grupo, os modelos criados por Von Thunen, Weber, Christaller, Isard e Losch. Deste modo, considera-se que o primeiro estudo voltado para a discussão regional foi o de Von Thunen, em que seu modelo matemático demonstra o ponto de maximização da renda da terra em várias localizações, onde são considerados os custos de transporte. Neste modelo, os produtos agrícolas seriam cultivados tendo por base os custos de transporte inversamente proporcionais à distância da cidade (CAVALCANTE, 2004).

Na teoria de localização de Alfred Weber são consideradas as questões de localização das indústrias, em que, além dos custos de transporte da matéria-prima, do produto acabado e os de mão de obra, considera-se também o fator localização.

Enquanto que a teoria do lugar central de Christaller busca compreender como são determinados o número, o tamanho e a distribuição das cidades, nomeadas como lugares centrais, que seriam responsáveis por distribuir bens e serviços para a região e para o seu entorno. Essa teoria não explica apenas o crescimento dentro de uma cidade, mas a distribuição espacial dos centros urbanos.

Já a teoria de Losch, que se assemelha com a de Christaller, propôs uma hierarquia entre as áreas de mercado buscando definir que, em dadas circunstâncias, todas as atividades se arranjarão no espaço.

Por fim, a teoria de Isard propõe um modelo que busca a localização ótima envolvendo a minimização dos custos de transporte. Tem-se que, até o ano 1956, quando foi publicada a teoria de Isard, a produção das teorias de localização eram publicadas apenas na língua alemã, o autor realizou uma síntese das teorias da escola clássica de localização e criou uma nova linha de pensamento denominada de Regional Science, em que diversos autores iniciaram uma adequação das teorias de acordo com a sua realidade regional (CAVALCANTE, 2004).

Foi apenas a partir da década de 1950, que vários autores passam escrever suas teorias de desenvolvimento regional com base nos conceitos ligados à questão da aglomeração, entre eles: Perroux, Myrdal e Hirschman.

Desse modo, François Perroux (1975) estipula que o crescimento econômico não ocorre de forma homogênea no espaço, e sim por meio de polos de crescimento que são induzidos pela instituição de uma empresa motriz em um determinado local, ou seja, com a instalação de uma indústria motriz em uma região não desenvolvida pode, por meio de seus efeitos, ocorrer a transformação desse local em polo de crescimento e influenciar no desenvolvimento da região onde foi instalada. 
Essa teoria defende a concentração dos investimentos para melhorar o aproveitamento dos efeitos de encadeamento, sendo que o ponto de partida para desencadear o processo de crescimento ocorre por meio da inserção de uma indústria motriz, que difundirá os efeitos de encadeamento para as atividades polarizadas. Porém, nesta teoria, os efeitos acumulativos de escala e de aglomeração, bem como os efeitos de demanda induzida de mercado, necessita da intervenção do Estado para ajustar os desequilíbrios regionais.

De uma forma diferente, Gunnar Myrdal (1972) define a teoria de causação circular cumulativa em que o desenvolvimento de uma região está condicionado à posição que ela ocupa dentro de um sistema de hierarquia de regiões, discutindo a heterogeneidade do desenvolvimento entre os países e as desigualdades regionais dentro dos países.

O referido autor define também que há um círculo vicioso que funciona como um agrupamento de forças que agem e reagem interdependentemente, mantendo um país pobre em estado de pobreza e é papel do Estado procurar diminuir as ações dos efeitos regressivos e aumentar os propulsores, intervindo em maior escala nos países não desenvolvidos, orientando, assim, todo o processo de desenvolvimento econômico deles.

A última teoria desse grupo refere-se a Albert Hirschman (1958), que trata do tema para os países subdesenvolvidos, contribuindo para um diagnóstico do não desenvolvimento e de possíveis soluções em sociedades que não dispunham de modelos de desenvolvimento econômico-social, o qual contestou outras teorias e a influência de intervenções estrangeiras nos países em crise.

Em suas análises, ele estipulou o que poderiam ser as possíveis causas do não desenvolvimento nos países subdesenvolvidos como, por exemplo, a escassez dos fatores de produção, a falta de capital, a falta de capacidade de tomada de decisão, entre outros. Um dos principais objetivos de seu estudo foi verificar como o processo de desenvolvimento pode ser passado de uma região para a outra.

Os efeitos para trás, da teoria de Hirschman, mostram as externalidades que são resultantes da implantação de uma indústria e melhorem a produção na região, e os efeitos para frente decorrem da oferta de insumos que torna os setores viáveis, fazendo com que surjam novas atividades devido à instalação de uma indústria, dessa forma, uma região pode se desenvolver caso haja atividades com a possibilidade de gerar encadeamentos.

Sendo assim, para o autor supra citado, o desenvolvimento não ocorre em todos os locais ao mesmo tempo e tende a se concentrar no ponto inicial do processo, quando ocorre o desenvolvimento em uma região, emergem movimentos de forças atuando em outras áreas, o que causa consequências econômicas tanto favoráveis quanto ruins ao mesmo tempo e, o que, em sua opinião, dificulta o desenvolvimento, são os círculos viciosos entrelaçados.

No último grupo de teorias regionais aqui apresentadas, se destacam autores como Michael Best e Michael Porter, entre outros, que focalizam suas análises para os efeitos positivos da concentração industrial sobre o desenvolvimento regional.

Focado na relação entre a competitividade das empresas e a concentração geográfica, Porter (1998) enfatiza o papel relevante da aglomeração que favorece devido aos custos reduzidos, o acesso a insumos, a serviços e a transportes. Tendo como base os benefícios da concentração geográfica e dos ganhos de escala no acesso à informação qualificada, Best (1993, p. 218) faz uma análise sobre a chamada "Terceira Itália", e afirma que:"Government economic policymakers in Emilia-Rogmana are aware that small and medium-sized firms must have access to economies of scale in the provision of both marketing and technological information if they are to remain competitive with vertically integrated firms".

Observa-se que, nos diversos conceitos anteriormente destacados, apresenta-se uma característica que é, em escala variada, comum a todos, ou seja, o aspecto endógeno dessas teorias no que se refere às suas relações com o desenvolvimento local.

Nota-se, também, que não é algo simples tentar estabelecer o que vem a ser desenvolvimento regional. Uma definição aqui aceita é a estipulada por Ademir Clemente e Hermes Higachi (2000) que definem desenvolvimento regional como sendo a elevação do nível de vida da população, tendo por base o desenvolvimento autossustentado, em que as riquezas naturais da região, juntamente com o fator humano, ou seja, seus costumes, culturas e práticas, adaptam a economia aos moldes de suas particularidades.

Sobre o desenvolvimento rural, conforme descreve Guilherme Delgado (2001), foi após a Segunda Guerra Mundial que começou ocorrer o processo de desenvolvimento da agropecuária brasileira. Essa expansão ocorreu de 1945 a 1980 , em que, com base nos princípios da Revolução Verde, houve uma reestruturação no setor utilizando-se de pacotes tecnológicos, do uso de fertilizantes, de defensivos agrícolas, da correção dos solos, da utilização de sementes melhoradas, além de máquinas industriais.

Desse modo, ocorre nesse período, também uma intervenção do Estado por meio de políticas públicas objetivando a modernização. Entre essas políticas adotadas, destacam-se as de subsídios de crédito, de preços mínimos e de assistência técnica. Com todas essas mudanças, há, também, alterações no modo de pensar a relevância da agricultura pelos estudiosos. Assim, a agricultura deixa de ser vista como secundária no processo de desenvolvimento, e a indústria como a única a trazer o desenvolvimento ao país.

Neste sentido, Zander Navarro (2001) argumenta que as teorias de desenvolvimento rural indicavam o fortalecimento tecnológico assim como o aumento da utilização de insumos, como meio para ampliação da produtividade e consequente aumento da renda dos produtores rurais. Ou seja, essas teorias de modernização agrícola preconizavam a especialização, seguiam a lógica do mercado, incentivavam a formação de commodities e o latifúndio. Além de estarem relacionadas ao conceito de crescimento, uma vez que visavam apenas ao aumento da produtividade e da renda. 
Este modo de pensar o desenvolvimento rural decai a partir do final dos anos de 1970 como consequência das transformações que aconteceram após os processos de reestruturação institucional e econômica, e também devido aos projetos de desenvolvimento rural não terem obtidos um desfecho satisfatório, conforme o esperado, em especial aos problemas ambientais advindos da revolução verde e por não ter havido uma redução do índice de pobreza conjecturado. A partir de então, passou-se a revisar os aspectos usados como referências teóricas para descrição do desenvolvimento rural (NAVARRO, 2001).

Deste modo, surge uma nova visão sobre o conceito de desenvolvimento rural fundamentado na noção multidimensional do desenvolvimento. Assim, o desenvolvimento rural passa a ser considerado como um procedimento que engloba os aspectos econômico, social, cultural, político, institucional e ambiental e não somente relacionado ao crescimento econômico visto por meio do aumento do PIB ou da renda (Kageyama,2004).

Neste mesmo sentido, Navarro (2001, p.88) traz uma definição de desenvolvimento rural como sendo: "uma ação previamente articulada que induz (ou pretende induzir) mudanças em um determinado ambiente rural”.

Nota-se que não há uma concordância sobre a definição de desenvolvimento rural, o que se tem é que esse conceito ainda está sendo elaborado, ou seja, em processo de elaboração. O referencial teórico encontrado até as últimas décadas, quando se procurava explicações para as alterações sociais, nos padrões tecnológicos das populações rurais e as consequências na qualidade de vida dos agricultores, estava relacionado com as teorias da modernização agrícola que fundava-se no conceito de Revolução Verde. Porém, já vem ocorrendo alterações significativas com relação ao conceito de desenvolvimento rural e em que se baseia (NAVARRO, 2001).

Schneider (2010) expõe que, a partir da década de 1990, o debate sobre o desenvolvimento rural está sendo encaminhado no sentido de considerar as ações de cunho normativo, relacionadas às políticas públicas e consequente interferência do Estado.

Para o referido autor, demais aspectos também colaboram para mudança de foco nesses debates, como, por exemplo, a complexidade em efetuar a reforma agrária, o reconhecimento político da agricultura familiar enquanto categoria, a integração de pontos ligados à sustentabilidade e questões ambientais como um todo, e as questões de ideologia e também politicas relacionadas às discussões: de um lado o agronegócio e do outro, a agricultura familiar.

Complementando, se torna preciso desconstruir a noção que vê como ideal o agricultor como um gestor rural especializado e ligado aos commodities, assim como é preciso também descontruir a noção do camponês autônomo, que se integra apenas à produção de subsistência.

Assim, o que se procura é a reconstrução de meios que possam viabilizar a diversificação da produção e de tecnologia, uma economia objetiva, meios de troca e de distribuição baseados nas relações sociais em que há os fundamentos da redistribuição e reciprocidade (Polanyi, 1944).

Deste modo, fica evidente que, para se fazer desenvolvimento rural, não é necessário somente incluir novos elementos em situações já estabelecidas, ou seja, não é possível pensar em desenvolvimento como sendo resultado da economia política, da mercantilização e da acumulação de capital, das políticas do Estado, das agências multilaterais, somente. Deste modo, precisa-se considerar o desenvolvimento como resultado de todos esses processos em conjunto com as circunstâncias específicas de cada espaço (Ploeg et al., 2000).

Finalizando essa discussão teórica de desenvolvimento rural, cabe destacar brevemente que, a partir do ano de 2003, com o novo Governo Federal que se distanciava das estratégias neoliberais global e se aproximava mais dos movimentos sociais, ocorreu um novo enfoque no diálogo político baseado nas políticas públicas e na relação com os movimentos sociais e na sociedade em si, a questão da fome, da segurança alimentar e de nutrição ganhou destaque, além de ser estabelecido um melhor relacionamento entre o Governo e os representantes da sociedade civil, para elaborar as políticas públicas. Uma dessas discussões diz respeito ao Fórum Agroecológico (WEID, 2006).

Assim, a questão agroecológica passou a ser incorporada nas discussões sobre os programas de crédito, de capacitação, de educação, de pesquisa e de assistência técnica voltados para a agricultura. Mas, mesmo que tenha tido destaque nos anos 2000, a discussão a respeito da agricultura agroecológica ou agricultura alternativa já era discutida desde os anos de 1980, no Brasil, onde, com a participação de movimentos sociais, de ONGs - Organizações Não Governamentais, de pesquisadores e dos próprios agricultores vinha-se buscando realizar experimentos neste aspecto visando à implantação de políticas públicas específicas para a agroecologia na agricultura.

Foi criada em 1983 a Rede PTA - Projetos e Tecnologias Alternativas que estava contida na FASE- Federação de Órgãos para a Assistência Social e Educacional. O objetivo da Rede era detectar os experimentos de tecnologias alternativas, agir nos processos sociais locais, disseminar os procedimentos adequados para cada caso distinto nas propriedades dos agricultores familiares. Já no final dos anos de 1990, a Rede PTA havia se consolidado em termos de experimentos locais e a todo o processo relacionado à agricultura agroecológica. Todavia, ainda faltava uma interligação nacional no âmbito da agricultura alternativa e, para tentar resolver esta questão, foi criada a ABA - Associação Brasileira de Agroecologia, que incorporava todos os envolvidos na agricultura orgânica, por meio das articulações dos movimentos sociais e redes que trabalhavam com a agricultura com um viés que se contrapunha a modernização agrícola nos padrões estabelecidos no país. Em 2002 foi criada a ANA - Articulação Nacional de Agroecologia, que era uma rede nacional de redes, instituições e organizações que objetivava a divulgação e a interligação entre eles, além de buscar meios para a defesa da agroecologia, que ia de encontro com o agronegócio, e também trazia sugestões de políticas públicas. 
Como resultado do trabalho da ANA, destaca-se a participação na formulação do PRONAF Agroecologia e no PRONAF Semiárido, o que representou o aceite de suas críticas quanto à forma de produção na qual o programa financiava, ou seja, com essa alteração houve uma mudança na base do PRONAF. Nota-se que a agroecologia surgiu como uma resposta socioambiental aos problemas advindos da Revolução Verde, como uma opção de transição dos modelos tradicionais de agricultura para um modelo de desenvolvimento rural sustentável. De acordo com Sevilla-Guzmán (2001, p. 11), a agroecologia é:

“o manejo ecológico dos recursos naturais através de formas de ação social coletiva, que representem alternativas ao atual modelo de manejo industrial dos recursos, mediante propostas sugeridas de seu potencial endógeno. Tais propostas pretendem um desenvolvimento participativo desde a produção até a circulação alternativa de seus produtos agrícolas, estabelecendo formas de produção e consumo que contribuam para encarar a atual crise ecológica e social".

Desta forma, a agroecologia se apresenta como uma fonte de referências tanto teóricas quanto práticas para auxiliar em uma nova abordagem com relação ao sistema agrário, alimentar e de sustentabilidade, ou seja, engloba aspectos econômicos, sociais e ecológicos.

\section{Considerações Finais}

Observou-se que, conforme a corrente de pensamento em que se enquadram, as definições de desenvolvimento sofrem variações.

Conclui-se que as formas de destituição, de exclusão e as desigualdades sociais comprimem ou anulam as liberdades efetivas de milhões de pessoas, num mundo que atingiu progressos materiais extraordinários, colocando a questão da necessidade de buscar formas de distribuição da riqueza gerada que permitam ampliar as liberdades efetivas de um número cada vez maior de pessoas, o que pressupõe a avaliação constante dos processos de geração e distribuição da riqueza.

Verificou-se que, para Sen (2001, p. 79), o bem-estar de uma pessoa pode ser concebido em termos da qualidade da condição da pessoa, "viver pode ser visto como consistindo num conjunto de "funcionamentos" inter-relacionados, que compreendem estados e ações". Assim, Sen estabelece uma teoria apta a nortear uma alternativa valorativa e racionalmente informada, o desenvolvimento como liberdade.

Defende-se que a sustentabilidade em si já é uma propriedade emergente sobre um diálogo a respeito do mundo em que se aspira viver. Assim, o desenvolvimento sustentável será possível se for conseguido novas parcerias e a criação de diálogos políticos com o envolvimento de um número maior de pessoas.

Ainda, com base nas teorias aqui apresentadas, destaca-se que a ideia de desenvolvimento regional, assim como sua conceituação, é diversa, por isso, apesar de terem sido apresentadas algumas teorias e definições, defende-se a ideia da concepção de desenvolvimento regional que ainda será trazida pelos atores sociais objetos da pesquisa de doutoramento- em andamentoconsiderando que os mesmos são os responsáveis pelas ações que conduzem para a melhora na qualidade de vida da região e consequente desenvolvimento.

Por fim, quanto ao desenvolvimento rural, conclui-se que a definição de desenvolvimento rural vem sofrendo alterações com o passar dos anos, mas um aspecto em comum dessas definições está relacionado à ênfase dada na busca pela melhoria do bem-estar no meio rural, sendo este o ponto principal para ocorrer o desenvolvimento. Assim, a definição de desenvolvimento rural pode ser entendida como o resultado de um projeto político instituído por meio da ação determinada dos atores sociais e das organizações relacionadas, assim como da sociedade como um todo (Ploeg et al., 2000).

\section{Referências}

ARBIX, Glauco; ZILBOVICIUS, Mauro; ABRAMOVAY, Ricardo. Desenvolvimento e instituições: a importância da explicação histórica. Razões e ficções do desenvolvimento. São Paulo: UNESP/EDUSP, 2001.

BEST, Michael. The new competition: institutions of industrial restructuring. Cambridge: Harvard University Press, 1993.

BRUM, Argemiro Jacob. O desenvolvimento econômico brasileiro. 22. ed. Petrópolis: Vozes, 2002.

CAVALCANTE, Luiz Ricardo Mattos Teixeira. Produção teórica em economia regional: uma proposta de sistematização. Salvador: Universidade Federal da Bahia - Escola de Administração, 2004.

CLEMENTE, Ademir; HIGACHI, Hermes. Economia e desenvolvimento regional. São Paulo: Atlas, 2000. 
COMISSÃO MUNDIAL SOBRE MEIO AMBIENTE E DESENVOLVIMENTO: NOSSO FUTURO COMUM. Rio de Janeiro: FGV, 1988. Disponível em: https://pt.scribd.com/doc/12906958/Relatorio-Brundtland-Nosso-FuturoComum-Em-Portugues. Acesso em: 05 abr 2017.

DELGADO, Guilherme da Costa. “Expansão e modernização do setor agropecuário no pós-guerra: um estudo da reflexão agrária", Estudos Avançados, v. 15, n. 43, p. 157-172. 2001.

ESTEVA, Gustavo. Desenvolvimento. In. SACHS, Wolfgang (editor). Dicionário do desenvolvimento: guia para o conhecimento como poder. Petrópolis: Vozes, 2000.

HADDAD, Paulo Roberto. (org). Economia regional: teorias e métodos de análise. Fortaleza: BNB, ETENE, 1989.

HIRSCHMAN, Albert O. The strategy of economic development. New Haven: Yale University Press,1958.

KAGEYAMA, Angela. Desenvolvimento rural: conceito e medida. Caderno de Ciência e Tecnologia, Brasilia, n.3, v. 21, p. 379-408, set-dez. 2004.

KRANZ, Patricia. Agenda 21: Vitoria do futuro. Vitoria: Secretaria Municipal de Meio ambiente, v. 1. 1997.

MALTHUS, Thomas Robert. Ensaios sobre a população. São Paulo, Editora Nova cultural, 1996.

MARSHALL, Alfred. Princípios da economia: tratado introdutório. São Paulo, Editora Nova cultural, 1996.

MYRDAL, Gunnar. Economic theory and under-developed regions. Gerald Duckworth \& CO. LTD: London, 1972.

NAVARRO, Zander. "Desenvolvimento rural no Brasil: os limites do passado e os caminhos do futuro",

Estudos Avançados, v. 15, n. 43, p. 83-100. 2001.

NISBET, Robert Alexander. História da ideia de progresso. Brasília: Editora Universidade de Brasília, 1985.

PERROUX, François. O conceito de pólo de crescimento. In: FAISSOL, S. Urbanização e regionalização: relações com o desenvolvimento econômico. Rio de janeiro, IBGE, 1975.

PLOEG Jan Douwe Vander; RENTING, Henk; BRUNORI G., KNICKEL K., MANNION J.,

MARSDEN T., ROEST K., SEVILLA-GUZMÁN E., VENTURA F., “Rural development: From practices and policies towards theory", Sociologia Ruralis, v.40, n. 4, p. 497-511, 2000.

POLANYI, Karl. The Great Transformation. Boston: Beacon Press, 1957. First edition, 1944.

PORTER, Michael. A vantagem competitiva das nações, 1998.

QUESNAY, François. Quadro econômico dos fisiocratas. São Paulo, Editora Nova cultural, 1996.

RICARDO, David. Princípios da economia política e tributação. São Paulo, Editora Nova cultural, 1996.

RICHARDSON, Harry. Economia regional- teoria da localização, estrutura urbana e crescimento regional. 2.ed. Rio de Janeiro, Zachar, 1981.

SACHS, Ignacy. Repensando o crescimento econômico e o progresso social: a âmbito da política. Razões e ficções do desenvolvimento. São Paulo: UNESP/EDUSP, p. 155-164, 2001.

SCHUMPETER, Joseph Alois. The Theory of Economic Development. Tradução Brasileira Abril Cultural. São Paulo - SP, 1982.

SEN, Amartya Kumar. A idéia de justiça. São Paulo: Companhia das Letras, 2011. 
SEN, Amartya Kumar. Rationality and Freedom. Cambridge, London: The Belknap Press of Harvard University Press, 2002.

SEN, Amartya Kumar. Desigualdade Reexaminada. Rio de Janeiro: Record, 2001.

SEN, Amartya Kumar. Desenvolvimento como liberdade. São Paulo: Companhia das Letras, 2000.

SEN, Amartya Kumar. Resources, Values and Development. Cambridge, London: Harvard University Press, 1998.

SEN, Amartya Kumar. "Radical Needs and Moderate Reforms". In: DREZE, Jean and SEN,Amartya (Eds.) Indian Development. Selected Regional Perspectives. Bombay, Calcutta,Madras: Oxford University Press. SEN,Amartya (Eds.) Indian Development. Selected Regional Perspectives. Bombay, Calcutta, Madras: Oxford University Press, 1997.

SEVILLA-GUZMÁN, Eduardo. As bases sociológicas. In: Encontro Internacional sobre Agroecologia e Desenvolvimento Rural Sustentável, 1. 2001, Botucatu. Anais- CDROM.V.1.

SMITH, Adam. A riqueza das nações: investigação sobre sua natureza e suas causas. São Paulo, Editora Nova cultural, 1996.

VARGAS, Paulo Rogerio. Rio +10: parceiras entre Brasil e a Alemanha para o desenvolvimento sustentável. Fortaleza: Fundação Konrad Adenauer.2002.

WEID, Jean Marc Von der. Construindo políticas públicas em apoio à agroecologia. Agriculturas, v.3, n.1, p.0406, 2006.

ZAMBAM, Neuro José. A teoria da justiça em John Rawls: uma leitura. Rio de Janeiro: Lumem Juris, 2016. 